\title{
It is impossible to know the way if we do not know where to start: tidal volume, driving pressure, and positive end-expiratory pressure
} É IMPOSSÍVEL SABER O CAMINHO SE NÃO SOUBERMOS POR ONDE COMEÇAR: VOLUME CORRENTE, DRIVING PRESSURE E PRESSÃO EXPIRATÓRIA FINAL POSITIVA

\author{
Marcelo Cunio Machado Fonseca ${ }^{1}$, Werther Brunow de Carvalho ${ }^{2 *}$ \\ ${ }^{1}$ Health Technologies Assessment Center, Universidade Federal de São Paulo, São Paulo, SP, Brazil \\ ${ }^{2}$ Full Professor of Pediatric Intensive Care/Neonatology of the Department of Pediatrics, Faculdade de Medicina da Universidade de São Paulo, São Paulo, SP, Brazil \\ ${ }^{*}$ Correspondence: \\ werther.brunow@hc.fm.usp.br
}

http://dx.doi.org/10.1590/1806-9282.63.01.1

Like many other technologies, mechanical ventilation has emerged out of necessity. Today, it is the basis of cardiopulmonary resuscitation, intensive medicine and anesthesia. Implementation of mechanical ventilation allows the treatment of several diseases that were previously lethal, and increases the survival of thousands of patients every day.

The lungs in acute respiratory distress syndrome (ARDS) are characteristically heterogeneous with an aereted area, called the baby lung, primarily located in non-dependent regions of the lung ${ }^{1}$ and areas where there is great inflammation, and the alveoli are filled with residual inflammatory material. It has been described that lungs with ARDS are not hardened but small, and that the compliance of this specific small aerated area is practically normal. ${ }^{2,3}$ The complacency of the respiratory system, in turn, is related to the functional size of the lung, that is, the remaining aerated volume. ${ }^{1}$

When this syndrome was described, the mechanical ventilation strategy used high flow volumes $(10-15 \mathrm{~mL} / \mathrm{kg})$ and relatively low positive end-expiratory pressure (PEEP) $\left(5-15 \mathrm{cmH}_{2} \mathrm{O}\right)$ with $\mathrm{FiO}_{2} \leq 0.70{ }^{4}$

Initially, we learned that this ventilatory strategy usually leads to ventilatory-induced lung injury (VILI) because it causes mechanical stress of the lung with overdistension and stretching of the pulmonary parenchyma (volutrauma). ${ }^{5}$ We know that VILI also occurs when there is low final expiratory volume. In this case, some bronchioles and alveoli will collapse during exhalation and reopen at the next inspiration, a process that damages the pulmonary parenchyma (atelectrauma) if this takes place repeatedly. ${ }^{5}$ Later, it was identified that the forms of mechanical ventilation that cause atelectrauma or volutrauma can lead to the release of inflammatory mediators in the lung, characterizing biotrauma. ${ }^{5}$ Together, it is theorized that there may be translocation of inflammatory mediators, bacteria or endotoxins into the systemic circulation due to the increased permeability caused by the underlying disease or biotrauma. This could eventually lead to multiple organ failure. ${ }^{6-8}$

In this context, and because we have not yet been able to demonstrate that a specific mode of mechanical ventilation improves patient survival, ${ }^{9}$ one of the major advances in the last decades has been the recognition of its complications, as described above, and the development of ventilatory techniques that minimize these complications. ${ }^{10}$

Ventilatory strategies that reduce the adverse effects of mechanical ventilation and at the same time are associated with better survival are referred to, in all, as protective ventilatory strategies. In general, these strategies involve the use of low tidal volume, low pressure at the end of inspiration (plateau pressure), and high PEEP.

Two systematic reviews by The Cochrane Collaboration, ${ }^{11,12}$ including six studies on ARDS, ${ }^{13-18}$ concluded that protective ventilatory strategies, specifically low tidal volume and low inspiratory plateau pressure, reduce hospital mortality and morbidity.

However, distinguishing which element has the greatest value for improving the clinical effects resulting from the protective ventilatory strategy is challenging, since each of them - low tidal volume, low inspiratory pressure (platean pressure), and high positive end-expiratory pressure -, is closely connected to the others.

Therefore, considering that, in ARDS, respiratory system complacency is related to the functional size of the lung, Amato et al. ${ }^{19}$ theorized that the ratio between tidal volume and respiratory system complacency, that is, driving pressure, would be an independent risk factor for survival in patients with ARDS.

To prove their theory, Amato et al. ${ }^{19}$ conducted a meta-analysis of individual patients with data from 3,562 patients enrolled in nine randomized clinical trials comparing mechanical ventilation strategies in ARDS. The authors' regression model showed that only four variables 
were associated with the outcomes; two were related to the patient, APACHE III or SAPS $(\mathrm{RR}=1.36)$ and arterial $\mathrm{pH}$ $(R R=0.73)$, and the other two were related to mechanical ventilation parameters, $\mathrm{FiO}_{2}(\mathrm{RR}=1.24)$ and driving pressure $(\mathrm{OR}=1.42)$. However, only exposure to high driving pressure during the first days of mechanical ventilation was strongly associated with a fixed and permanent risk over the first 60 days after randomization, thus satisfying the proportional hazards hypothesis. By analyzing the driving pressure more closely, the authors were able to demonstrate that with a fixed PEEP, increased driving pressure leads to increased mortality. On the other hand, when we progressively increase PEEP and maintain the driving pressure fixed, there is no effect on mortality, but if we decrease the driving pressure, we also reduce mortality. Thus, the association of driving pressure with mortality was evidenced. Thus, an association between driving pressure and mortality was evident. Furthermore, in a series of additional analyzes, Amato et al. showed that in patients receiving protective mechanical ventilation (platean pressure $\leq 30 \mathrm{cmH}_{2} \mathrm{O}$ and $\mathrm{TV} \leq 7 \mathrm{~mL} / \mathrm{kg}$ for an ideal weight) a driving pressure of less than $13 \mathrm{cmH}_{2} 0$ generates less mortality, while a platean pressure $>$ or $\leq 26 \mathrm{cmH}_{2} 0$ or TV $>$ or $\leq 7 \mathrm{~mL} / \mathrm{kg}$ for the ideal body weight has no effect on mortality.

If we consider these new evidences relevant and apply them to the bedside, the main ways of manipulating ventilatory parameters to benefit patients are to reduce tidal volume and adjust PEEP level. The effect of decreasing tidal volume has already been pointed out in the ARDSNet Tidal Volume trial, ${ }^{20}$ which showed that the group of patients receiving low tidal volumes had lower mortality. Not coincidentally, this group also had a lower driving pressure, with a difference of $-8.8 \mathrm{cmH}_{2} \mathrm{O}$ compared to the group of higher tidal volumes. The three largest randomized controlled trials comparing high versus low PEEP in patients with ARDS failed to demonstrate benefit in relation to the mortality of elevated PEEP. What probably happened was that the changes in driving pressure in these studies ${ }^{21-23}$ were not important enough, $-2.8,-0.2,+0.2$, respectively, to produce a difference in mortality. And this, in turn, may have occurred because in each patient the high PEEP had conflicting consequences: either it reduced VILI by decreasing atelectrauma, or it increased it as a result of overdistension. Given the heterogeneity of the lung with ARDS, "recruitability" is difficult to anticipate, and so adjusting PEEP is of paramount importance.

Thus, the first step is to determine whether the patient has recruitable lungs. Grasso et al. demonstrated that in patients with recruitable lungs, the use of high PEEP causes the $\mathrm{PaO}_{2} / \mathrm{FiO}_{2}$ ratio to increase and, in contrast, it does not change in patients with non-recruitable lungs. ${ }^{24} \mathrm{Next}$, we must determine the optimal PEEP. At this moment, the findings of Amato et al. are of fundamental importance. The adjustment of optimal PEEP can be performed by determining the PEEP resulting in lower driving pressure, preferably less than $14 \mathrm{cmH}_{2} \mathrm{O} .{ }^{19}$ This can be done by increasing or decreasing PEEP by $4 \mathrm{cmH}_{2} \mathrm{O}$ at a time, and measuring the driving pressure at each pressure level. Increases or decreases smaller than this can cause problems in the signal/noise ratio. These small additions or decreases in PEEP should be made until the driving pressure reaches its lowest value. If this point is exceeded, the driving pressure increases again. Also in favor of the driving pressure, there is no need for special equipment to measure it, the pressure can be observed directly from the mechanical ventilation device without paralyzing the patient, who only has to be relaxed during exhalation of the gases so that the measured platean pressure is more reliable.

Recently, Gattinoni et al. ${ }^{25}$ presented an interesting proposal that energy supplied per unit of time ("power") is an entity that unifies most of the parameters used in mechanical ventilation, in addition to the relevant forces involved in the genesis of VILI, providing us with a "composite index" that can be transposed into clinical practice, as it evaluates the relative contribution of adjustable components at the bedside (TV, frequency, PEEP, $\Delta$ airway pressure, I:E ration, flow).

One should emphasize that because ARDS is distinguished by the heterogeneity of pulmonary involvement as well as by conflicting responses to the therapies implemented, such as maintaining high PEEPs, evaluation by means of images of the adequacy of mechanical ventilation is fundamental. The gold standard for mechanical ventilation monitoring in ARDS, however, is computed tomography, despite its disadvantages due to risks related to the transport of patients and their excessive exposure to radiation, which reduces its applicability. ${ }^{1}$ On the other hand, there is electrical impedance tomography, which seems to be a very appropriate alternative, providing continuous monitoring in real time, without the need for radiation or patient transport. This test reliably shows changes in lung volume and tidal volume. ${ }^{1,26}$

The strategies of protective ventilation are effectively a breakthrough. They allow the reduction of mortality despite the partial understanding of how this benefit is achieved. The additional understanding provided by Amato et al. ${ }^{19}$ solved an old issue while simultaneously providing key elements for reducing mortality and allowing us to establish a strategy for optimum PEEP adjustment, friendly to the professionals and which does not require special equipment. 
Mechanical ventilation in ARDS remains a major challenge for intensive care physicians, but newly aggregated knowledge and the new technologies available open a new perspective on the path that will still be pursued.

\section{References}

1. Ochiai R. Mechanical ventilation of acute respiratory distress syndrome. J Intensive Care. 2015; 3(1):25.

2. Gattinoni L, Pesenti A, Avalli L, Rossi F, Bombino M. Pressure-volume curve of total respiratory system in acute respiratory failure. Computed tomographic scan study. Am Rev Respir Dis. 1987; 136(3):730-6.

3. Gattinoni L, D'Andrea L, Pelosi P, Vitale G, Pesenti A, Fumagalli R. Regional effects and mechanism of positive end-expiratory pressure in early adult respiratory distress syndrome. JAMA. 1993; 269(16):2122-7.

4. Petty TL, Ashbaugh DG. The adult respiratory distress syndrome. Clinical features, factors influencing prognosis and principles of management. Chest. 1971; 60(3):233-9

5. Tremblay LN, Slutsky AS. Ventilator-induced lung injury: from the bench to the bedside. Intensive Care Med. 2006; 32(1):24-33.

6. Tremblay L, Valenza F, Ribeiro SP, Li J, Slutsky AS. Injurious ventilatory strategies increase cytokines and c-fos m-RNA expression in an isolated rat lung model. J Clin Invest. 1997; 99(5):944-52.

7. Imai Y, Parodo J, Kajikawa O, de Perrot M, Fischer S, Edwards V, et al Injurious mechanical ventilation and end-organ epithelial cell apoptosis and organ dysfunction in an experimental model of acute respiratory distress syndrome.. JAMA. 2003; 289(16):2104-12.

8. Slutsky AS, Ranieri VM. Ventilator-induced lung injury. N Engl J Med. 2013; 369(22):2126-36

9. Kotur P. Mechanical ventilation - Past, present and future. Indian J Anaesth 2004; 48(6):430-2

10. Slutsky AS. History of mechanical ventilation. From Vesalius to ventilatorinduced lung injury. Am J Respir Crit Care Med. 2015; 191(10):1106-15.

11. Petrucci N, Iacovelli W. Lung protective ventilation strategy for the acute respiratory distress syndrome. Cochrane Database Syst Rev. 2007; (3):CD003844

12. Petrucci N, De Feo C. Lung protective ventilation strategy for the acute respiratory distress syndrome. Cochrane Database Syst Rev. 2013; (2):CD003844.

13. Amato MB, Barbas CS, Medeiros DM, Magaldi RB, Schettino GP, LorenziFilho $G$, et al. Effect of a protective-ventilation strategy on mortality in the acute respiratory distress syndrome. N Engl J Med. 1998; 338(6):347-54.

14. Ventilation with lower tidal volumes as compared with traditional tidal volumes for acute lung injury and the acute respiratory distress syndrome.
The Acute Respiratory Distress Syndrome Network. N Engl J Med. 2000; 342(18):1301-8.

15. Brochard L, Roudot-Thoraval F, Roupie E, Delclaux C, Chastre J, FernandezMondéjar E, et al. Tidal volume reduction for prevention of ventilator induced lung injury in acute respiratory distress syndrome. The Multicenter Trail Group on Tidal Volume reduction in ARDS. Am J Respir Crit Care Med. 1998; 158(6):1831-8.

16. Brower RG, Shanholtz CB, Fessler HE, Shade DM, White P Jr, Wiener CM, et al. Prospective, randomized, controlled clinical trial comparing traditional versus reduced tidal volume ventilation in acute respiratory distress syndrome patients. Crit Care Med. 1999; 27(8):1492-8.

17. Stewart TE, Meade MO, Cook DJ, Granton JT, Hodder RV, Lapinsky SE, et al. Evaluation of a ventilation strategy to prevent barotrauma in patients at high risk for acute respiratory distress syndrome. Pressure- and VolumeLimited Ventilation Strategy Group. N Engl J Med. 1998; 338(6):355-61.

18. Villar J, Kacmarek RM, Pérez-Méndez L, Aguirre-Jaime A. A high positive end-expiratory pressure, low tidal volume ventilatory strategy improves outcome in persistent acute respiratory distress syndrome: a randomized, controlled trial. Crit Care Med. 2006; 34(5):1311-8.

19. Amato MB, Meade MO, Slutsky AS, Brochard L, Costa EL, Schoenfeld DA et al. Driving pressure and survival in the acute respiratory distress syndrome. N Engl J Med. 2015; 372(8):747-55.

20. Ventilation with lower tidal volumes as compared with traditional tidal volumes for acute lung injury and the acute respiratory distress syndrome. The Acute Respiratory Distress Syndrome Network. N Engl J Med. 2000; 342(18):1301-8.

21. Brower RG, Lanken PN, MacIntyre N, Matthay MA, Morris A, Ancukiewicz M, et al.; National Heart, Lung, and Blood Institute ARDS Clinical Trials Network Higher versus lower positive end-expiratory pressures in patients with the acute respiratory distress syndrome. N Engl J Med. 2004; 351(4):327-36.

22. Meade MO, Cook DJ, Guyatt GH, Slutsky AS, Arabi YM, Cooper DJ, et al.; Lung Open Ventilation Study Investigators. Ventilation strategy using low tidal volumes, recruitment maneuvers, and high positive end-expiratory pressure for acute lung injury. JAMA. 2008; 299(6):637-45.

23. Mercat A, Richard JC, Vielle B, Jaber S, Osman D, Diehl JL, et al.; Expiratory Pressure (Express) Study Group. Positive end-expiratory pressure setting in adults with acute lung injury and acute respiratory distress syndrome: a randomized controlled trial. JAMA. 2008; 299(6):646-55.

24. Grasso S, Fanelli V, Cafarelli A, Anaclerio R, Amabile M, Ancona G, et al. Effects of high versus low positive end-expiratory pressures in acute respiratory distress syndrome. Am J Respir Crit Care Med. 2005; 171(9):1002-8.

25. Gattinoni L, Tonetti T, Cressoni M, Cadringher P, Herrmann P, Moerer O, et al. Ventilator-related causes of lung injury: the mechanical power. Intensive Care Med. 2016; 42(10):1567-75

26. de Carvalho WB, Fonseca MC, Johnston C. Electric impedance tomography, the final frontier is close: the bedside reality. Crit Care Med. 2007; 35(8):1996-7. 